\title{
Research on the Incentive Mechanism of the Armed Police Force financial cadres based on content motivation theory
}

\author{
Zhang Jing \\ Logistics University of PAP, No.1, Hui Zhihuan Road, Dong Li District, Tianjin, China
}

383540984@qq.com

\begin{abstract}
Keywords: content motivation theory, Armed Police Force, financial cadre, incentive mechanism Abstract. Content motivation theory focuses on the content , the structure and the dynamic action of the need of people. This paper first introduces related concepts of content motivation theory, then analyzes the existing problems of current incentive mechanism of Armed Police Force financial cadres. And puts forward some specific methods of establishing more perfect financial cadre incentive mechanism from meeting the three aspects of financial cadres' needs: the development needs, esteem and emotional needs, achievement needs. These methods have certain reference significance for actual work.
\end{abstract}

\section{Introduction}

The financial department of internal business division of labor is more and more detailed. Financial real-time security, precise security has gradually become the basic requirement of accurate financial departments at all levels. Therefore, higher requirements are asked in the management work of financial cadres. However, the status quo of financial incentive mechanism of the Armed Police Force is not perfect at present. For the incentive means and methods are relatively simple, so cannot give full play to the potential of financial cadres cannot be fully played, and the enthusiasm in financial working cannot be motivated. How to further perfect the incentive mechanism of Armed Police Force financial cadres and optimize the structure of financial cadres has become a realistic problem in front of the Party leadership at all levels.

\section{An overview of content motivation theory}

Content motivation theory is also known as the theory of needs, the emphasis of the study mainly lies in inspiring, supporting and suspending the incentive object to make some beneficial behavior motivation factors for organization. Content based incentive theory think that people are encouraged to the extent depends on the degree of the need to be satisfied. The theory mainly consists of the following four parts.

First, Maslow's Hierarchy of Needs Theory. Maslow was an famous American behavioral scientist, he thought that people in need can be divided into five layers from low to high: physiological needs, security needs, belongingness and love needs, respect needs and self-actualization needs, according to the level of the hierarchy of needs.

Second, Herzberg's Two-Factor Theory. Herzberg divided the work related factors into two types: one is a kind of "incentive factors" that can meet the needs of people, including the recognition of work, achievements, the responsibility, superior recognition, promotion and so on. The other is "health factors". This kind of factors can eliminate people's discontent, and thus indirectly play an incentive role of motivation, including working conditions, interpersonal relationship, work remuneration and so on.

Third, Alderfer's ERG theory. This theory divided the human needs into three major categories: the demand of existence, the demand of relationship and the demand of growth.

Fourth, McClelland's achievement motivation theory. The theory focuses on three types of needs: the need of achievement, the need of power and the need of belonging. 
The above four kinds of theories discuss how to more effectively stimulate people's enthusiasm from different emphasis of incentive content. The core idea of the theories has certain reference function for the optimization of Armed Police Force financial cadre incentive mechanism.

\section{The main existing problems of current incentive mechanism of Armed Police Force financial cadres}

\subsection{The cadre training mechanism is not reasonable enough}

The current financial cadres training cannot make a good incentive guiding role. And the training effect is not obvious. On the one hand, the financial cadre students which are trained have different knowledge base, and they all come from different and wide district. So the guiding function of training is not obvious. On the other hand, training courses are unitary, and they cannot combine the different realities of different units, dampening the study enthusiasm of the finance cadres which are trained.

\subsection{Sufficient attention are not given for financial cadres}

Financial work is an important part of logistics system. And its function is more and more outstanding. It is the key to configure the financial resources, coordination different kinds of economic relations and construct modern logistics. However, the level of attention for financial cadres in Armed Police Force is still not high enough. The good atmosphere of "respecting talents" has not formed. Some leading cadres don't have a good understanding of the financial work. Some of them even have prejudice on financial work, they think that financial work is just an ordinary work which focuses on managing and accounting money. This kind of bias can easily lead to erroneous idea that financial institutions are of no great importance to be produced in the troops. And the scientific cadre appointment and training may be neglected. It is very unfavorable for the development of improving the development level of financial and human resources. And the work enthusiasm of financial cadres can be dampened. Obviously, It is not conducive for financial system construction and long-term development.

\subsection{Lacking the promotion and development space for financial cadres}

At present, the pyramid form of military financial management system and restriction of financial department's organization determine the development space of financial cadres is very limited, especially the detachment (group) level units. Sometimes financial cadres have to leave the financial sector in order to get promotion opportunities. Therefore, the average working life of financial cadres is short. What's more, in the financial sector, different positions of financial cadres can master one kind of operation such as budget management, asset management, business accounting and so on only after a period of training. However, financial cadres have to conduct job rotation on a regular basis. So some of them facing the situation of reorientation going to the grass-roots to train themselves. These factors have led to little space for financial cadres to promote and develop. It is not conducive to stimulate the financial cadre's greatest potential.

\section{Construct and perfect the incentive mechanism of the Armed Police Force financial cadres based on the content motivation theory}

\subsection{Meet the needs of development}

\subsubsection{Reference position configuration and optimize the selection mechanism}

First, establish a "green channel" to cultivate and transport excellent financial reserve cadres between military academies and the financial sectors. And assign the financial graduates to finance departments as much as possible. In order to ensure that more than $90 \%$ of the financial professional 
graduates can work in professional counterparts after graduation and prevent the loss of financial talent. Second, adhere to the qualification system. Undocumented appointment of financial cadres should be prohibited in military. That is to say, all of the financial workers must pass the Armed Police Force or local accounting qualification examination and the certified rate must reach $100 \%$. Thus the financial work can be further regulated.

\subsubsection{Improve the cultivation mechanism based on the tasks}

Adhere to the principle of combining cultivating and appointing financial cadres. First of all, control the source of training object. The department of cadres should specify the requirements of training object's education background and professional background when they issue education training target to each unit. And the cadres who have no financial professional knowledge and practical background should be avoided to attend training courses which may result in a waste of financial resources for training. At the same time, establish a concept of comprehensive training and comprehensive ability training. In an effort to improve the moral and technical quality of financial cadres. And it is also necessary to emphasize the cultivation of the cadres' learning ability, innovation ability and practice ability.

\subsection{Meet the needs of emotion and respect}

\subsubsection{Understand the importance of financial work correctly and improve the level of attention}

We can create a good atmosphere of attaching great importance for financial work by propagandizing and training method. And the prejudice such as "financial work is just accounting money" should be eliminated. Understand the importance of financial work correctly and comprehensively. Pay attention to the cultivation of financial talents. Improve the level of financial work effectively so as to improve the utilization efficiency of PAP's funds and drive the construction and development of modern logistics.

\subsubsection{Improve the service level for talents and create new circumstance by innovation system}

First, further strengthen logistics service commitment system. And effectively improve the logistics and service ability in order to liberate the cadres from economic worry and make all their heart and soul into work. Second, create cadres growth platform actively. Give priority to meritorious award or job promotion for the cadres which have perfect ideological style, high professional quality and great potential of development. We should create a good atmosphere of "respect for labor, respect knowledge, respect for talent and respect for creation". Encourage and support the cadres who work hard. Incentive, condenses and stabilize the talents with common beliefs and pursuit value.

\subsection{Meet the needs of achievement}

\subsubsection{Optimization the evaluation system and create a fair competitive environment}

First of all, improve the annual evaluation system. Divide the financial leading cadres into groups according to the level of the unit's financial construction and the responsibility of cadres. Establish a scientific evaluation index system according to different evaluation subjects. Secondly, conduct a track inspection system. Compose a special investigation group each year. And this group can inspect the performance of financial cadres at all levels and the work situation in several forms, such as field survey, follow-up interviews and comprehensive analysis. And the group should focus on whether the financial unit leadership is responsible and whether they accomplish work timely and in high quality. Specifically examine the political attitude, work style, work ability, work performance of 
financial leading cadres, which is used as an important basis for meritorious award and create fair competition environment for financial cadres.

\subsubsection{Establish an excellent cadre incentive system and stimulate the work enthusiasm of financial cadres}

Establish and perfect the financial cadre reward system based on the reward of Armed Police Force headquarters. And the system should reward as the main body of the units and departments at various levels. Study and formulate excellent cadre financial incentives and focus on rewarding the financial cadres which have made outstanding contributions. Perfect the financial cadres selection recognition system. Set up the typical model in order to guide every unit to select excellent financial cadres and organize corresponding recognition activities. In addition, the appraisal results and rewards should be combined strongly. The financial cadres who have outstanding achievement assessment and performance must be awarded, and they can be taken into consideration preferentially when there are opportunities such as training, promoting, evaluating professional title and so on. What's more, the units which have enough financial resource can hand out bonuses for material reward.

\section{Summary}

This paper puts forward some specific methods of establishing more perfect financial cadre incentive mechanism from meeting the three aspects of financial cadres' needs: the development needs, esteem and emotional needs, achievement needs. These methods have certain reference significance for actual work. But the methods which were provided in this paper are still not detailed and comprehensive. We need to further improve in the next research.

\section{References}

[1] Cohen A., An evaluation \& reconceptualization of organizational commitment [J], Human Resource Management Review 2007, 17:336-354.

[2] Ping Zhang, Yang Zhang, Hongyu Guan. Incentive Mechanisms of Altruistic Behavior with Social Preference Introduced and the Effects Comparison [J]. Canadian Social Science, 2015, 119:.

[3] Renjian Feng, Shenyun Che, Xiao Wang, Jiangwen Wan. An incentive mechanism based on game theory for trust management [J]. Security Comm. Networks, 2014, 712:.

[4] Killeen P R. Incentive theory: II. Models for choice [J]. Journal of the Experimental Analysis of Behavior, 1982, 382:.

[5] David A. Volkman, Kath Henebry. The use of Incentive contracting and Firm Reputation[J]. Corporate Reputation Review, 2010(4):8-18. 